\title{
Medical Students' Perspective about Attributes of Role Models - The Other Side of Story
}

Fatima Aslam¹, Unaiza Jawad², Usman Amin Hotiana ${ }^{3}$, Usman Mahboob4, Sara Ashfaq ${ }^{5}$, Muhammad Youshay Jawad ${ }^{6}$

\author{
${ }^{1}$ Department of Psychiatry \& Behavioural Sciences, Avicenna Medical College \& Hospital, Lahore, \\ Pakistan. 2, 3.Department of Psychiatry \& Behavioural Sciences, Rashid Latif Medical College \& Hospital, \\ Lahore, Pakistan. ${ }^{4}$ Department of Medical Education, Institute of Health Profession Education \& \\ Research, Khyber Medical University, Peshawar, Pakistan. ${ }^{5}$ Department of Endocrinology, Shaukat \\ Khanum Memorial Cancer Hospital \& Research Center, Lahore, Pakistan. ${ }^{6}$ Department of Psychiatry \& \\ Behavioural Sciences, King Edward Medical University \& Mayo Hospital, Lahore, Pakistan.
}

\section{ABSTRACT}

\section{BACKGROUND}

Role modelling exponentially affects the attitude and behaviours of medical students and act as a key factor in developing professional attributes in them. Medical students observe role models and learn from them more than through formal teaching. This study investigates the determining elements that make a teacher a role model, so that role modelling can be used as an effective educational tool.

\section{METHODS}

A qualitative exploratory study was conducted on fifth year medical students of three medical colleges of Lahore, Pakistan. Fifteen, telephonic, semi structured interviews were included in the study. Thematic analysis was done by manual coding of transcribed interviews.

\section{RESULTS}

A total of 374 codes were generated in the first cycle of coding, that were further merged to 42 in the second cycle. These codes led to 5 subthemes that finally emerged as two themes. The first theme was "Finding ways around their blaring blunders - are we blind?" highlighting the attributes of negative role models which include humiliation of students and juniors, poor teaching and communication skills, lack of empathy for patients and unethical relationship with pharmaceutical industry. The second theme was "Walking the Line" focusing on the components of positive role modelling like formal workplace attire, candid approach in teaching, strategic dealing with students, empathetic attitude towards patients and prioritising fair treatments.

\section{CONCLUSIONS}

Medical education is not only about acquisition of new knowledge and skills but is also about acquiring physician's character and identity. The study findings suggest that the medical students pay attention to both positive and negative attributes of their teachers and their influence on promoting professionalism and character development. It is suggested that both teachers and administrators should understand the significance of role models and advocate excellence in role modelling.

\section{KEY WORDS}

Role Models, Professional Development, Medical Student, Medical Teacher

\author{
Corresponding Author: \\ Fatima Aslam, \\ Assistant Professor, \\ Department of Psychiatry \& Behavioural \\ Sciences, Avicenna Medical \\ College \& Hospital, \\ Lahore, Pakistan. \\ E-mail: dulcie16@gmail.com
}

DOI: $10.14260 /$ jemds/2021/350

How to Cite This Article:

Aslam F, Jawad U, Hotiana UA, et al. Medical students' perspective about attributes of role models - the other side of story. $J$ Evolution Med Dent Sci 2021;10(22):16921697, DOI: 10.14260/jemds/2021/350

Submission 23-01-2021,

Peer Review 02-04-2021,

Acceptance 08-04-2021,

Published 31-05-2021.

Copyright (C) 2021 Fatima Aslam et al. This is an open access article distributed under Creative Commons Attribution License [Attribution 4.0 International (CC BY 4.0)] 


\section{BACKGROUND}

In medical education, teachers play a pivotal role in students' professional development and in shaping up their identity. Role modelling is considered as a fundamental source for learning humanistic and ethical aspects of healthcare. From the undergraduate level, medical students are provided with different learning and observing opportunities and are constantly interacting with a variety of potential role models, some of whom are inclined towards negative behaviours more, than positive professional behaviours. ${ }^{1}$ Mainstay of teaching professionalism has been through role models, ${ }^{2}$ and it is of utmost importance that these role models present healthy and positive learning atmosphere for medical undergraduates. ${ }^{3}$

Role modelling usually takes place in informal and hidden part of institution's curriculum. There is large amount of data available that shows significance of role modelling in medical education. This phenomenon is well understood, and a lot of earlier studies have highlighted different components and typologies of role modelling. Positive role models (PRM) are those who can be copied and imitated for their behaviours, humane and professional conduct and negative role models (NRM) are examples to be avoided. ${ }^{4}$

As doctors play a multifaceted role in hospitals, not only as residents but also as teachers and health care providers, their attitude can have a major effect on medical students and patients, respectively. The impact and significance of professional attitude have been a topic of interest for medical educationists and they have tried to inculcate it, in basic as well as specialist training of all healthcare professionals. ${ }^{5}$

Keis et al. surveyed the German medical students in clinical rotations called "Famulatur", about their experience and expected traits in potential role models from a group of healthcare professionals. Most teachers were found to be positive inspirations as compared to negative ones. Junior residents were the most commonly perceived role models as they are usually the person in charge for matters of undergraduate medical students followed by consultants. The highly likeable traits included behaviour with students followed by professional expertise and humanistic characteristics. Whereas in consultants, professional competence and excellent teaching skills were found to be important aspect of positive role modelling. Being arrogant and uncooperative during teamwork and humiliating behaviour with students and patients made the consultants poor examples of role models. ${ }^{6}$ Interaction with clinical teachers and physicians, who used to display a lack of empathy for patients and used derogatory humour within teaching was a source of disappointment for students reported in a qualitative study in University of Sydney. Students identified negative role models as having poor understanding of curriculum and assessment requirements, lack of enthusiasm for teaching and humiliation of students. ${ }^{7}$

Healthcare related graduates are in large number in Asia catering to the needs of an ever growing and understaffed medical manpower. ${ }^{8}$ We can bring out a healthy and progressive transformation in this region by instilling medical education units, an increased interest in adopting evidenceinformed teaching-learning methods and curricular reviews. ${ }^{9}$ However, as most of the research in this field is based in other continents and may not have covered all aspects of role models, therefore it's not very locally relevant. ${ }^{10}$ In Pakistan, there has been little research on role modelling; thus, given the significant effect of role models in all areas of education and their efficacious impact on personality formation, identity and professional behaviour of medical students, this study was an attempt to fill this gap using a qualitative design.

\section{METHODS}

An exploratory qualitative study was carried out over a period of six months (Jan - June 2020) in three medical colleges of Lahore. Ethical approval and permissions were sought from principals of selected medical colleges. A purposive convenience sample of fifteen medical students of fifth year was selected having more than or equal to $75 \%$ class and clinical ward attendance. An interview guide was developed including a brief introduction about the nature of the study and its objective, interview questions and how the confidentiality of participants will be maintained. The interview questions were validated by five medical education experts and then piloted with three students to ensure clarity. Informed consent was taken, and students were briefed about the voluntary nature of participation. To ensure confidentiality and anonymity, participants were given code names from student $\mathrm{A}$ to $\mathrm{O}$. All the interviews were audio recorded and transcribed verbatim. Thematic analysis was used to examine patterns within the data. The authors familiarised themselves with the data by going through each segment repeatedly. In the next step, codes were generated manually to get rich description of data set. Later the codes were merged to form sub-themes and themes. The analysis was done by first, second and third author independently and themes were discussed and agreed upon to ensure analytical triangulation. COREQ-32 checklist was employed to ensure the quality of this study. ${ }^{11}$ Reflexivity and personal attributes of research team were controlled by adding comments by the researchers to create an open and honest narrative that will resonate well with readers and respondents chose the time of convenience and exercised their control over process in telephonic interviews.

\section{RESULTS}

\begin{tabular}{|c|c|c|}
\hline Themes & Sub-Themes & Codes \\
\hline \multirow[t]{2}{*}{$\begin{array}{l}\text { Finding ways } \\
\text { around their blaring } \\
\text { blunders: Are we } \\
\text { blind? }\end{array}$} & $\begin{array}{l}\text { Lack of } \\
\text { commitment to } \\
\text { profession }\end{array}$ & $\begin{array}{l}\text { Insensitivity towards plight of patients \& } \\
\text { attendants } \\
\text { Condescending behaviour with juniors } \\
\text { Reproachful behaviour of teachers towards } \\
\text { students } \\
\text { Deficient in teaching skills } \\
\text { Ineffective patient dealing } \\
\text { Callous dealings for petty financial gains } \\
\text { Doctors \& pharmaceutical companies; a } \\
\text { lucrative link }\end{array}$ \\
\hline & $\begin{array}{l}\text { Reasons of } \\
\text { misconduct }\end{array}$ & $\begin{array}{l}\text { Casual dressing is better in long working } \\
\text { hours } \\
\text { Doctors take out their own stress \& } \\
\text { frustration on patients } \\
\text { Spiteful malicious personality of teachers }\end{array}$ \\
\hline Walking the line & $\begin{array}{l}\text { Positive attributes } \\
\text { of a role model }\end{array}$ & $\begin{array}{c}\text { Formal workplace attire } \\
\text { Candid approach in teaching \& } \\
\text { strategic dealing with students } \\
\text { Empathic attitude towards patients \& } \\
\text { prioritising fair treatment }\end{array}$ \\
\hline & 1. 1nemes with & S Sub-Themes and Codes \\
\hline
\end{tabular}


Fifteen medical students of fifth year participated in this study, out of whom, eight were females and seven were male students. Five students from each medical college voiced their opinion in qualitative interviews. Two themes along with five sub-themes were identified from data analysis. (Table 1)

\section{Finding Ways Around Their Blaring Blunders: Are We Blind?}

The first theme that emerged out of data was about the unprofessional behaviours being depicted by medical teachers in both academic and clinical settings. (Table 2)

Ten out of fifteen medical students were of the opinion that teachers display rude behaviour with patients and their attendants in clinical interactions in the presence of students. Students felt bad when senior doctors showed lack of empathy for patient's needs and worries. According to medical students, doctors do not like patients to give personal opinions or discuss their concerns regarding the disease during clinical interactions. They want patients to just listen and comply with their orders. Many students expressed their concern regarding the reproachful behaviour of teachers with them during teaching sessions. Excessive criticism on minor mistakes and passing personal comments has been a norm in educational institutes as reported by students. Similarly, judgement and discrimination by role models on the basis of level of knowledge and alma mater was quite a disappointment for medical students. Medical students considered good teaching skills as a part of positive role modelling and value tutors who create a positive learning environment. Eleven students stated that majority of teachers and clinicians lack teaching skills. Effective communication skills were considered an essential element of doctor-patient relationship and participants felt that most of the junior doctors were less practiced and did not know how to deliver information to their patients.

Thirteen participants mentioned cases of professional lapses like prescribing excessive medications, getting unnecessary investigations by seniors in order to make money and abusing the professional relationship with pharmaceutical companies for personal gains, considering them highly unethical. The study participants witnessed some similar events while observing their role models at work. During the interviews, many participants remarked that long working hours and exhaustion could be one of the few reasons of misconduct by seniors. Whereas some had the opinion that deficiencies in individual character and competence can result in persistent unprofessional behaviours.

\section{Walking the Line}

Positive attributes of role models being conceived by medical students was the second theme developed from the interview transcripts. (Table 3) According to two third of our study participants, a doctor must dress up in a serious and nonprovoking attire. It is the duty of a health professional to make the patient comfortable and should not give them an image of self-neglect. A role model is expected to have theoretical knowledge as well as a set of skills which include verbal communication, patient management, teaching and research. Eleven students thought that those teachers who observe good manners, show compassion towards others, provide guidance, and support to students, and help them to improve their selfesteem are considered to be positive role models. Optimal patient care and adherence to pillars of medical ethics is required by health professionals under all circumstances as repeatedly suggested by medical students.

\begin{tabular}{|c|c|c|}
\hline Sub-Themes & Codes & Representative Quotations \\
\hline \multirow{6}{*}{$\begin{array}{l}\text { Lack of } \\
\text { commitment to } \\
\text { profession }\end{array}$} & $\begin{array}{l}\text { Insensitivity } \\
\text { towards plight of } \\
\text { patients \& } \\
\text { attendants }\end{array}$ & $\begin{array}{l}\text { "I have seen teachers in operation theatre (OT) } \\
\text { while preparing for a C-section and the } \\
\text { anaesthetist and other staff were making fun of } \\
\text { the patient who was in pain. Patient felt that } \\
\text { and became more anxious and stressed. They } \\
\text { played with her emotions, instead of giving her } \\
\text { care and empathy. Professionalism is required } \\
\text { even if it is their daily work and part of routine." } \\
\text { (Participant B) }\end{array}$ \\
\hline & $\begin{array}{l}\text { Condescending } \\
\text { behaviour with } \\
\text { juniors }\end{array}$ & $\begin{array}{l}\text { "I observed a senior medical specialist passing } \\
\text { derogatory comments on a junior about his } \\
\text { level of knowledge while he was taking our } \\
\text { ward class. Even if it was needed, it should have } \\
\text { been done in private. It felt bad and all students } \\
\text { disliked this approach of senior doctor." } \\
\text { (Participant 0) }\end{array}$ \\
\hline & $\begin{array}{l}\text { Reproachful } \\
\text { behaviour with } \\
\text { students }\end{array}$ & $\begin{array}{l}\text { "In our surgery ward rotation, we encountered } \\
\text { a teacher who used to humiliate us just because } \\
\text { we were from different college than him. He } \\
\text { was a Kemcolian, teaching in our institute. } \\
\text { Whenever, we were unable to answer his } \\
\text { question, he used to criticise our institute and } \\
\text { our level of knowledge. This discrimination } \\
\text { made us feel bad and demotivated us." } \\
\text { (Participant K) }\end{array}$ \\
\hline & $\begin{array}{c}\text { Deficient in } \\
\text { teaching skills }\end{array}$ & $\begin{array}{l}\text { "Teachers have great knowledge, but they do } \\
\text { not know how to deliver. We are at loss, then } \\
\text { we turn to seniors or YouTube for knowledge } \\
\text { and skills. We feel, all here are not out to be } \\
\text { teachers. I rate their teaching skills } 5 \text { / 10." } \\
\text { (Participant E) }\end{array}$ \\
\hline & $\begin{array}{c}\text { Ineffective } \\
\text { patient dealing }\end{array}$ & $\begin{array}{l}\text { "Communication skills are extremely poor in } \\
\text { hospitals and staff do not listen and explain } \\
\text { things at patient level. Lumbar puncture was } \\
\text { done on a patient and he was not given any } \\
\text { information about his disease and diagnostic } \\
\text { test beforehand. In Pakistan we are lacking in } \\
\text { this field. It has a negative effect on us that } \\
\text { teacher does not know how to communicate } \\
\text { with patient." (Participant G) }\end{array}$ \\
\hline & $\begin{array}{l}\text { Callous dealings } \\
\text { for petty financial } \\
\text { gains }\end{array}$ & $\begin{array}{l}\text { "I saw a doctor treating a patient who had a } \\
\text { foreign body stuck in throat. It took him few } \\
\text { seconds to remove it, yet he charged the patient } \\
\text { a huge sum of money. I think you should charge } \\
\text { according to work done. There is a trend } \\
\text { nowadays that doctors over prescribe / over } \\
\text { charge attendants when at times, patient is } \\
\text { lying dead in intensive care unit (ICU) thus, } \\
\text { making money when it is of no use to patient. } \\
\text { In reality, they are earning hellfire for } \\
\text { themselves." (Participant B) }\end{array}$ \\
\hline \multirow{3}{*}{$\begin{array}{l}\text { Reasons of } \\
\text { misconduct }\end{array}$} & $\begin{array}{l}\text { Casual dressing is } \\
\text { better in long } \\
\text { working hours }\end{array}$ & $\begin{array}{l}\text { "Many doctors do not follow dress code, and I } \\
\text { feel it is wrong. They say they have long hours } \\
\text { of work, so they need to dress casual and } \\
\text { comfortable." (Participant K) }\end{array}$ \\
\hline & $\begin{array}{l}\text { Doctors take out } \\
\text { their own stress } \\
\text { \& frustration on } \\
\text { patients }\end{array}$ & $\begin{array}{l}\text { "I have seen PGRs misbehaving and shouting at } \\
\text { patients when they make a mistake. I felt bad } \\
\text { and considered them wrong as there are some } \\
\text { morals but over time, I realised that those } \\
\text { doctors are exhausted from long duty hours and } \\
\text { personal stresses and that causes them to act } \\
\text { like this." (Participant I) }\end{array}$ \\
\hline & $\begin{array}{l}\text { Spiteful malicious } \\
\text { personality of } \\
\text { teachers }\end{array}$ & $\begin{array}{l}\text { "There is a teacher in our college, who once gets } \\
\text { a bad impression of student, continues to insult, } \\
\text { s and criticise him / her for the rest of year, no } \\
\text { matter how much effort, student makes } \\
\text { afterwards to erase the bad image. I realised, } \\
\text { this is his personality and he humiliated us just } \\
\text { to feed his ego." (Participant N) }\end{array}$ \\
\hline
\end{tabular}




\begin{tabular}{|c|c|c|}
\hline Sub-Themes & Codes & Representative Quotations \\
\hline \multirow{3}{*}{$\begin{array}{l}\text { Positive attributes } \\
\text { of a role model }\end{array}$} & $\begin{array}{l}\text { Formal workplace } \\
\text { attire }\end{array}$ & $\begin{array}{l}\text { "There should be a dress code as dressing at } \\
\text { workplace shows your professionalism like } \\
\text { wearing a white coat makes you look like a } \\
\text { doctor and people interact accordingly. It } \\
\text { enhances your personality and makes your } \\
\text { first impression and both students and } \\
\text { patients make a perception about a doctor } \\
\text { initially by the dress they are wearing." } \\
\text { (Participant C) }\end{array}$ \\
\hline & $\begin{array}{l}\text { Candid approach in } \\
\text { teaching \& strategic } \\
\text { dealing with } \\
\text { students }\end{array}$ & $\begin{array}{l}\text { "I consider a person to be a teacher, who is } \\
\text { approachable and committed to teaching but } \\
\text { if someone lacks that, I do not consider them } \\
\text { teacher. I have one such teacher in medical } \\
\text { college who had no knowledge and if } \\
\text { without books he could not answer our } \\
\text { questions. Teachers should come prepared } \\
\text { so that they can guide students and answer } \\
\text { their questions properly." (Participant B) }\end{array}$ \\
\hline & $\begin{array}{l}\text { Empathic attitude } \\
\text { towards patients \& } \\
\text { prioritising fair } \\
\text { treatment }\end{array}$ & $\begin{array}{c}\text { "Socioeconomic level of patient should be } \\
\text { kept in mind when advising medicines. If a } \\
\text { patient tells himself, he has issue of } \\
\text { affordability then the doctor must try to } \\
\text { accommodate his constraints and not deny } \\
\text { healthcare. Doctor should fix a reasonable } \\
\text { fee structure so that he can see patients } \\
\text { from all walks of life where he takes care of } \\
\text { poor and also earns decent from rich ones." } \\
\text { (Participant K) }\end{array}$ \\
\hline \multicolumn{3}{|c|}{ Table 3. Walking the Line } \\
\hline
\end{tabular}

\section{DISCUSSION}

The doctor-patient relationship is primarily affected by a key factor i.e. how professional the doctor's behaviour is, towards his / her patient. So the recognition of these behaviours is imperative in adopting a progressive professional life. ${ }^{12}$ This study elucidates the undesirable behaviours in medical professionals which include lack of empathy towards patients, mistreatment with juniors and medical students, ineffective communication and teaching skills and the negative influence of physician-pharmaceutical industry relationship on patient care thus, jeopardising the public's trust. Unprofessional behaviours that interfere in following the pillars of medical ethics like beneficence and non-maleficence while treating patients involve prescribing excessive medications, ordering unnecessary procedures for financial gains, breaching their confidentiality and lack of respect and compassion for patients. Twenty Korean residents from 17 clinical departments of internal medicine, general surgery, paediatrics, obstetrics and gynaecology and psychiatry reported being involved in similar kinds of misconducts during their residency program in a qualitative, exploratory study in a tertiary hospital. ${ }^{13}$ Other categories in unethical behaviours included violating the rules and regulations of workplace, fabricating research data and mistreating interprofessional colleagues. A single resident admitted being involved in such misconducts between 3 to 18 number of times and median number was 7.4.

Toxic practice alternatively known as pimping phenomenon refers to a clinical situation in which a medical teacher humiliates a student who could not come up to expected performance levels. These medical teachers are of the viewpoint that such public humiliation and embarrassing feedback can lead to an improvement in performance by student in future. In our study while mentioning the negative attributes of role models, students were of the opinion that usage of degradation as a teaching tool is a norm of many medical schools. These findings are consistent with a mixed method study in which $85 \%$ of Nigerian medical students $(\mathrm{N}$
= 52) reported having experienced belittling behaviour by teachers during clinical rotations in hospitals. Unfortunately, most of these students did not report the event to anyone as they felt, nothing could be done about it and some mentioning fear of reprisal. On the other hand, $30.7 \%$ of students took this experience as a standard procedure of instruction in medical education and some considered it useful for learning, making them more resilient. ${ }^{14}$

Keeping in mind the existence of hierarchal structure in medical profession, junior doctors may be particularly vulnerable to bullying and workplace incivility. Llewellyn et al. explored the rate of exposure to bullying in junior doctors in New South Wales, Australia in a mixed method study and found that almost half of the participants $(\mathrm{N}=203)$ experienced bullying and they were reluctant to speak out due to same reasons as mentioned by medical students. ${ }^{15}$ The participants of our study wanted their role models to have a well-prepared approach in teaching with updated knowledge and rich content. According to Iranian nursing students, lack of expertise of teachers in scientific knowledge and poor teaching methodologies was found to be one of the leading causes of uncivil behaviour in them. Moreover, students stated that unclear learning objectives in class and inability to guide students, negatively affects their learning process. ${ }^{16}$

According to our study participants, lack of communication skills is even more important than having less knowledge. Poor communication in a physician-patient interaction and provision of substandard care (12.9\% and 25 $\%$ respectively) were the most frequently reported dilemmas being witnessed quite frequently by Nigerian medical students of final year $(\mathrm{N}=100)$ in faculty members during a crosssectional survey. The reason can be that medical ethics are not an explicit part of medical curriculum of Nigerian medical schools and the only exposure for the medical students may be through informal ethical teaching during hospital training. ${ }^{17}$

Interactions between pharmaceutical industry and healthcare professionals are a widespread practice. Physicians' prescribing behaviour is affected by this relationship according to our study findings as conflict of interest can arise between physicians' duty to patient and monetary well-being of pharmaceutical industry. In a recent study, $74 \%$ of Saudi physicians ( $N=300)$ admitted meeting with pharmaceutical representatives frequently, however, 61 $\%$ of them denied the fact that their prescribing behaviour is affected by any kind of promotional activities which is in contrast to our study findings. More than two-third of the respondents admitted industry sponsored continuous medical education (CME) events are mostly presented as endorsement gifts to them. These results can be due to respondent bias as the participants were physicians and they may have tried to answer in an ethically acceptable manner. ${ }^{18}$

The participants in our study considered professional lapses as acceptable to some extent keeping in mind the busy duty schedules, overworked physicians, and malicious personality attributes. Similar findings were reported in a quantitative 23-item tool based on Pritzker School of Medicine survey, in Turkish medical school where the students from clinical years $(\mathrm{N}=104)$ were more likely to rationalise the deviant behaviour of teachers when they considered them normal and specifically after observing and participating in them as opposed to preclinical years $(\mathrm{N}=111)$. These behaviours include making fun of peers, passing derogatory remarks to patients, being introduced as doctor to patients and 
discussing patients in public places. ${ }^{19}$ The low response from preclinical students can be due to their less exposure to the clinical environment as compared to students in clinical years.

Our study participants argued that most probable reason of casual dressing by teachers at workplace can be long working hours. On the contrary, a recent study on physicians' perception on attire hypothesised several other reasons like limited white coat availability issued by institutes, inadequate laundry facility in hospitals and regional climate. ${ }^{20}$

Stressful environment, heavy workload, and complex nature of patients' presentations in emergency department can result in professional lapses by clinicians and other staff as experienced by nurses of Iran. Another reason might be the inability to cope with their stress and frustration thus, lashing out on other colleague's around.21 Bradley and associates surveyed 606 doctors in three teaching hospitals of England followed by two focus group discussions in 2015. According to participants, some individuals and departments were habitually rude with negative personality traits, showing aggressive and disrespectful behaviour to junior doctors and students thus confirming our study findings. ${ }^{22}$

Medical physicians have been given clear guidelines by Hippocrates, about the dress code based on their professional and hygienic requirements. Hippocrates stated that a physician should carry a well-groomed and pleasing personality at all times. ${ }^{23}$ Our study participants pointed out that a positive role model must have an appropriate professional attire as students and patients are influenced and make an impression about their degree of knowledge, professionalism, competency, and experience. Somewhat same results were noted in a multi-institutional study conducted in USA and Australia looking into perceptions of students and faculty members about physicians' clinical attire. Keeping in mind, the multi-cultural nature in both cohorts and the climate variations of two continents, it was found that USA students (58\%) and faculty members (88\%) were more in favour of white coat and neckties as compared to their Australian counterparts (59\% and $43 \%$ respectively). However, all cohorts of study were supportive of dress code policies to direct the health professionals towards an appropriate and acceptable workplace attire. Casual attire like jeans, t-shirts and untucked shirts in males and low-cut necklines and short length shirts in females were generally considered unsuitable and inappropriate. The most interesting finding of this study was that medical students from both continents quoted that their dressing was most influenced by the physicians' workplace attire (38\%) as compared with the course being taught on medical ethics (5 $\%)^{23}$

In another mixed method study in Australia, the students in graduate entry medical program emphasised on the development of rapport with students by showing patience and understanding and highlighted the importance of teaching at the level, appropriate for students with an understanding of how little, first year students know (22 \% and $20 \%$ respectively). Majority of students wanted their role models to have a good knowledge of curriculum, learning objectives and importance of constructive feedback. ${ }^{24}$

Among the countless fields existing around the world, medical profession holds a unique and prestigious position and general public keep the members of this profession on a high pedestal. To maintain peoples' trust, it is the obligation of physician to respect and observe professional values like prioritising the best interest of patient over their personal gain while taking professional decisions. The first draft of guidelines for professional conduct in medical practice in Iran was developed in 2017 by taking opinion of all stakeholders i.e. consultants, residents, and medical students. It comprised of six chapters with concepts mainly focusing on altruism, honesty, justice, excellence, and professional responsibility. According to these guidelines, it is the duty of a health professional to prioritise the patient's interest, fix enough time for every consultation and attend to the concerns and plight of patients. They should treat the patients justly without discrimination of gender, ethnicity and socioeconomic status. ${ }^{25}$ This is in consistent with the findings of our study in which medical students emphasized on the importance of empathic attitude towards patients and prioritising fair treatment.

\section{CONCLUSIONS}

Professional development of students is mostly influenced by teachers they encounter during their education and role models are considered the most effective source of learning as compared to formal teaching. This study investigated the attributes of positive and negative role models and categorised the findings into two themes. The teachers who humiliate students and juniors, have poor communication and teaching skills, lack empathy for patients and maintain a lucrative bond with pharmaceutical industry on the expense of patient care were considered negative role models. Excellence in role modelling requires display of exemplary clinical care; teaching expertise and individual humanistic qualities and our study findings reinforce these attributes desirable in positive role models.

\section{Limitations}

Our study was limited to only medical students of fifth year MBBS programmes. Taking views of students from other years and dental and allied health programmes would have added to educational value. Two private and one government medical school was used for data collection, but the comparison was not done between views of students from both set-ups, rather a more holistic approach was used to develop themes. We excluded other stakeholders like faculty in this study which would have broadened the scope of this research project.

Data sharing statement provided by the authors is available with the full text of this article at jemds.com.

Financial or other competing interests: None.

Disclosure forms provided by the authors are available with the full text of this article at jemds.com.

We are thankful to all the participants and head of institutes where the study was conducted.

\section{REFERENCES}

[1] Hendelman W, Byszewski A. Formation of medical student professional identity: categorizing lapses of professionalism and the learning environment. BMC Med Educ 2014;14(139):1-10.

[2] Birden H, Glass N, Wilson $\mathrm{I}$, et al. Teaching professionalism in medical education: a Best Evidence 
Medical Education (BEME) systematic review. BEME Guide No. 25. Med Teach 2013;35(7):e1252-66.

[3] Franco RS, Franco CAG, Kusma SZ, et al. To participate or not participate in unprofessional behaviour-is that the question? Med Teach 2017;39(2):212-9.

[4] Bijari BB, Zare M, Haghdoost AA, et al. Factors associated with students perceptions of role modelling. Int J Med Educ 2016;7:333-9.

[5] Chang HJ, Lee YM, Lee YH, et al. Causes of resident lapses in professional conduct during the training : a qualitative study on the perspectives of residents. Med Teach 2017;39(3):278-84.

[6] Keis O, Schneider A, Heindl F, et al. How do German medical students perceive role models during clinical placements (Famulatur)? An empirical study. BMC Med Educ 2019;19(1):184.

[7] Burgess A, Goulston K, Oates K. Role modelling of clinical tutors: a focus group study among medical students. BMC Med Educ 2015;15:17.

[8] Shankar PR, Piryani RM. Medical education and medical educators in south Asia--a set of challenges. J Coll Physicians Surg Pak 2009;19(1):52-6.

[9] Lam TP, Lam YYB. Medical education reform: the Asian experience. Acad Med 2009;84(9):1313-7.

[10] Jayasuriya-Illesinghe V, Nazeer I, Athauda L, et al. Role models and teachers: medical students perception of teaching-learning methods in clinical settings, a qualitative study from Sri Lanka. BMC Med Educ 2016;16:52.

[11] Tong A, Sainsbury P, Craig J. Consolidated criteria for Reporting Qualitative Research (COREQ): a 32-item checklist for interviews and focus groups. Int J Qual Heal Care 2007;19(6):349-57.

[12] Jamalabadi Z, Ebrahimi S. Medical students' experiences and perspective on unprofessional behavior in clinical practice. J Adv Med Educ Prof 2018;6(1):31-6.

[13] Chang HJ, Lee YM, Lee YH, et al. Investigation of unethical and unprofessional behavior in Korean residency training. Teach Learn Med 2015;27(4):370-8.

[14] Olasoji HO. Broadening conceptions of medical student mistreatment during clinical teaching: message from a study of toxic phenomenon during bedside teaching. Adv Med Educ Pract 2018;9:483-94.
[15] Llewellyn A, Karageorge A, Nash L, et al. Bullying and sexual harassment of junior doctors in New South Wales, Australia: rate and reporting outcomes. Aust Heal Rev 2019;43(3):328-34.

[16] Rad M, Ildarabadi E, Moharreri F, et al. Causes of incivility in Iranian nursing students: a qualitative study. Int J Community Based Nurs Midwifery 2016;4(1):47-56.

[17] Okoye O, Nwachukwu D, Maduka-Okafor FC. Must we remain blind to undergraduate medical ethics education in Africa? A cross-sectional study of Nigerian medical students. BMC Med Ethics 2017;18(73):18.

[18] Bahammam S, Asiri S, Al-Jahdali Y, et al. Attitudes and behaviours of physicians towards the relationship with the pharmaceutical industry in Saudi Arabia. East Mediterr Heal J 2020;26(3):323-30.

[19] Kulac E, Sezik M, Asci H, et al. Medical students participation in and perception of unprofessional behaviors: comparison of preclinical and clinical phases. Adv Physiol Educ 2013;37(4):298-302.

[20] Verghese BG, Kashinath SK, Jadhav N, et al. Physician attire: physicians perspectives on attire in a community hospital setting among non-surgical specialties. J Community Hosp Intern Med Perspect 2020;10(1):1-5.

[21] Parizad N, Hassankhani H, Rahmani A, et al. Nurses experiences of unprofessional behaviors in the emergency department : a qualitative study. Nurs Heal Sci 2018;20(1):54-9.

[22] Bradley V, Liddle S, Shaw R, et al. Sticks and stones: investigating rude, dismissive and aggressive communication between doctors. Clin Med (Lond) 2015;15(6):541-5.

[23] Bramstedt KA, Colaco CMG, De Silva E, et al. Perceptions of US and Australian medical students and instructors about clinical professional attire: lapel study. J Am Osteopat Assoc 2016;116(4):244-54.

[24] Burgess A, Oates K, Goulston K. Role modelling in medical education: the importance of teaching skills. Clin Teach 2016;13(2):134-7.

[25] Tehrani SS, Nayeri F, Parsapoor A, et al. Development of the first guideline for professional conduct in medical practice in Iran. Arch Iran Med 2017;20(1):12-5. 